\title{
Finite Element Analysis of Unreinforced Masonry Walls
}

\author{
Mohammed S. Mohammed \\ Assistant Lecture
}

Civil Engg. Dep./College of Engg. /Mosul University

\begin{abstract}
In the present work nonlinear finite element program written in fortran language to simulate the behavior of masonry wall under the action of monotonic loading has been developed. The masonry is modeled as a two-phase material, treating bricks and mortar joints separately, thus allowing for nonlinear deformation characteristic and progressive local failure of both bricks and mortar joints. The influence of the mortar joint is taken into account by using an interface cap model as a part of a rational unit-joint model able to describe cracking, slipping and crushing of the material. The capabilities of the program have been examined and demonstrated by analyzing two different types of masonry wall. The accuracy of the analytical results was assessed by comparing them with the experimental results and shown to be good.
\end{abstract}

Key words: Interface element, Masonry Wall, Nonlinear behavior.

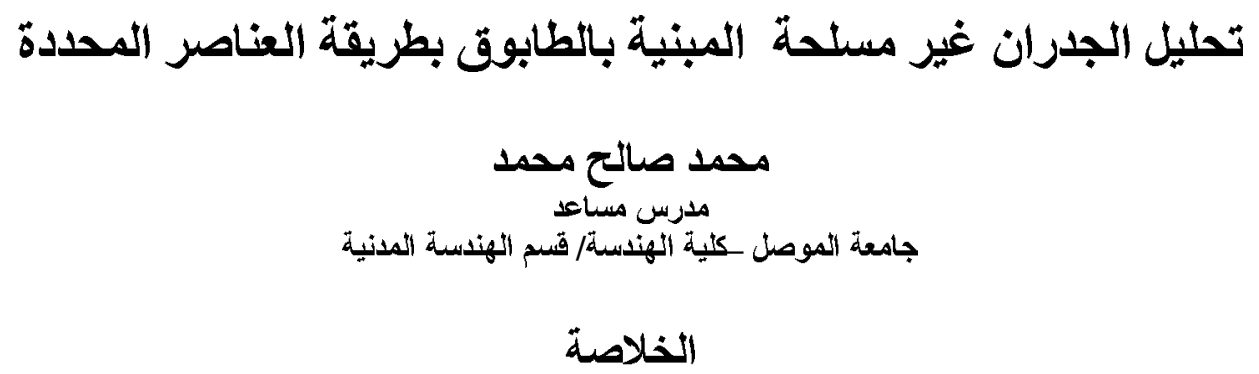

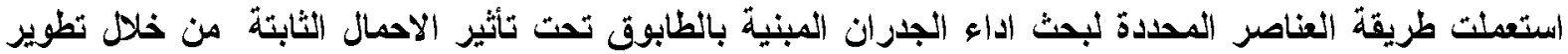

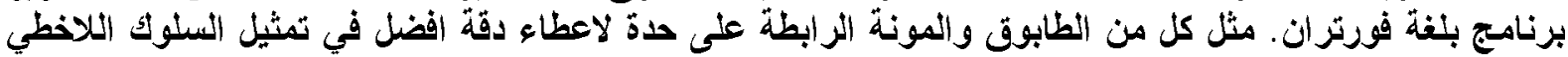

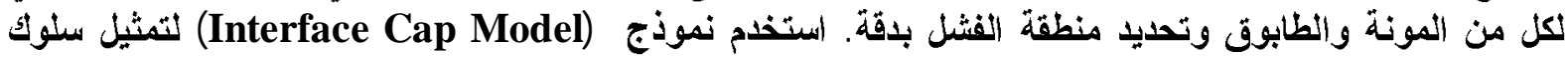

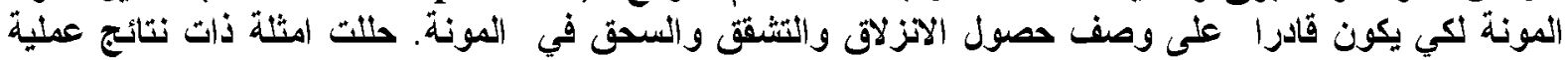

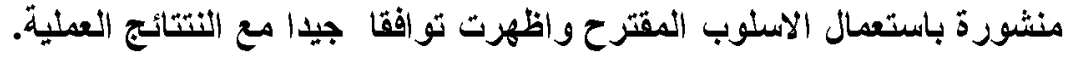




\section{1-Introduction}

In recent years, there has been an interest study in the mechanics of unreinforced masonry structures, with the aim to provide efficient tools for better understanding of their complex behavior. Mortar joints usually present a lower strength than masonry units, so explaining the existence of plane of weakness along which cracks propagate to failure. Therefore, two main approaches have been developed for the constitutive description of masonry, usually known in the technical literature as macro-modeling and micro-modeling [1].

In macro-modeling masonry, no distinction between the individual units and joints is made, and masonry is considered as a homogeneous, isotropic, or anisotropic continum. As macromodeling of masonry is advantageous when the global behavior of the structure is important. The influence of the mortar joints acting as planes of weakness cannot be addressed.

The alternative micro-modeling approach, expanded units are modeled with continuum elements, while the behavior of the mortar joints and unit-mortar interface is lumped as discontinuous line interface elements [2]. In this research micro-modeling has been adopted in preference to the macro-model.

The behavior of masonry wall under in plane loading has been the subject of many investigations. Dhansekar etal [3] proposed nonlinear finite element model for solid masonry based on average properties derived from biaxial tests on brick masonry panels.

Page[4] presented a method that accounts the nonlinear behavior of masonry, where the masonry is considered as a two-phase material. Ali and Page [5] also used the method to study the nonlinear behavior of masonry subjected to concentrated loads. However all these models include only tensile (brittle) and shear failure (brittle or elastic/ideal plastic) of the joint. A number of plasticity-based continuous -interface models have been developed to model the tension and shear behavior of masonry -mortar joints [6].

Lourenco [7] recently used both micro-modeling and macro-modeling to represente masonry wall. In this model the gradual softening behavior in the model for interface element was used and the elastic model was used to represent behavior of the brick of wall.

In this search, nonlinear bidimensional finite element models are used to simulate fracture in masonry structures. Masonry consists of bricks, which is modeled with eight quadratic plane stress elements. Interface elements are used to simulate the joints. The plasticity model proposed by Lourenco [7 ] is used to formulate a modern algorithmic plasticity concepts. These include implicit Euler backward return mapping schemes and consistent tangent operators .Including a correct handling of the corners. The model is formulated in the context of non-associated plasticity. The analysis is carried out with a special arc-length control that automatically search for the largest relative displacement in the interfaces. Numerical implementation of the model is evaluated by a comparism between numerical results with the experimental results for the case of masonry wall with in plane loading.

\section{2-Finite element model of the present study}

In the finite element analysis conducted here, masonry is treated with micro-model, in which the units of brick and joints are modeled individually with different type of elements. The masonry units are modeled with smeared crack elements, which account for both tensile and compressive fracture of the units, while the mortar joints are modeled with interface element to account for the inherent planes of weakness to include all the basic types of failure mechanisms that characterize masonry, see Fig. 1. 
(b)

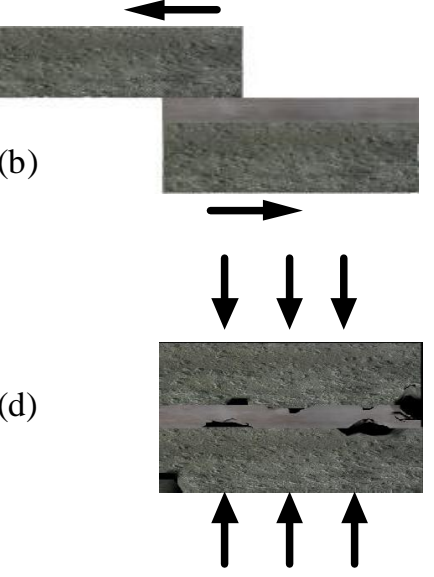

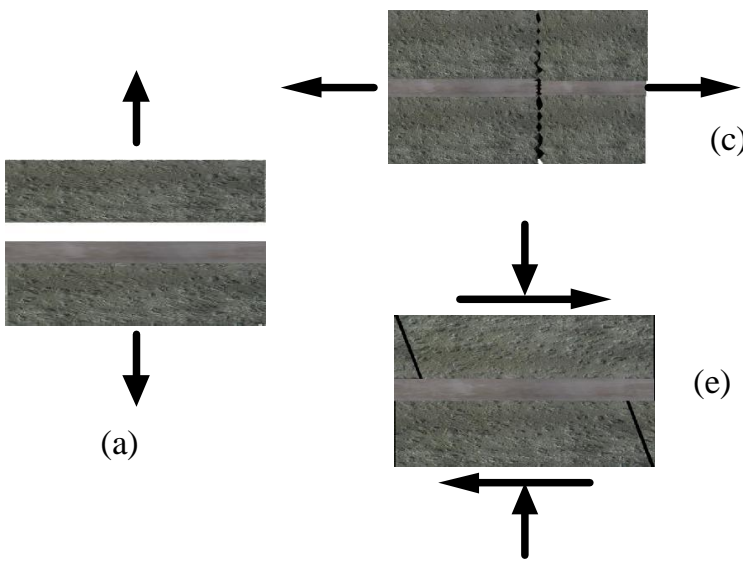

Fig.(1) Masonry failure mechanisms: (a) joint displacement; (b) joint slipping; (c) unit direct tensile cracking; (d) masonry crushing; (e) unit diagonal tensile cracking.

\subsection{Masonry units}

Isoperimetric plane-stress element with eight-noded and smeared crack pattern is used to model the behavior of masonry units as shown in Fig. 2.

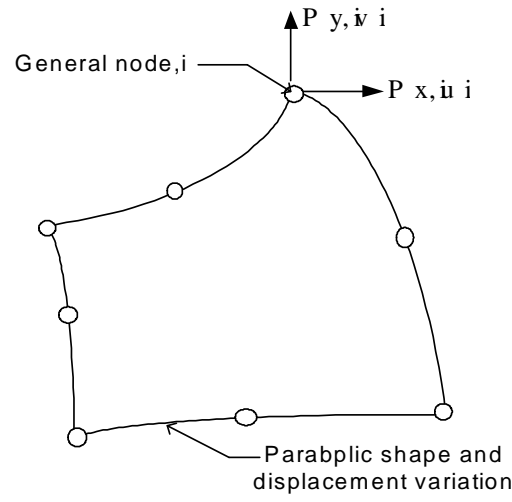

Fig.( 2) Typical 8-node isoperimetric element

Material nonlinearities due to cracking of concrete, plastic flow or crushing of the unit in compression are considered. The compressive failure and tensile fracture of masonry are governed by a von Mises failure surface with tension cutoff as shown in Fig.3, in which $\sigma_{1}$ and $\sigma_{2}$ are the principal stresses, $f_{m}$ and $f_{t}$ are compressive and tensile strength of masonry, and $f_{o}$ determines the initial yield surface which is also governed by the Von Mises criterion where assumed in this research to be $0.5 f_{m}$. Before the tension cutoff surface is reached, the material is assumed to be elastic-plastic, of which the plastic behavior is represented by $J_{2}$ plasticity as soon as the stress state reaches the initial yield surface. The material exhibits a strain-hardening behavior when the stress state is between the initial yield surface and the final failure surface. Strain softening occurs once the final yield surface is reached. The von Mises failure criterion can be expressed as follows.

$J_{2}-\sigma_{e}^{2}\left(\varepsilon_{p}\right)=0$

(1)

In which $J_{2}$ is the second invariant of the deviatoric stress, and $\sigma_{e}$ and $\varepsilon_{p}$ represent the effective stress and effective plastic strain respectively. A crack is initiated when the 
maximum principle stress reaches the tensile strength, in direction normal to the maximum principle stress at each Gauss point. The cracked element is assumed to be nonlinear orthotropic material. The crushing type of unit is a strain-controlled phenomenon .A simple way is used by converting the yield criterion in stresses into the yield criterion directly in terms of the strain. The details of the plasticity model and smeared crack model can be found in Ref. [10].

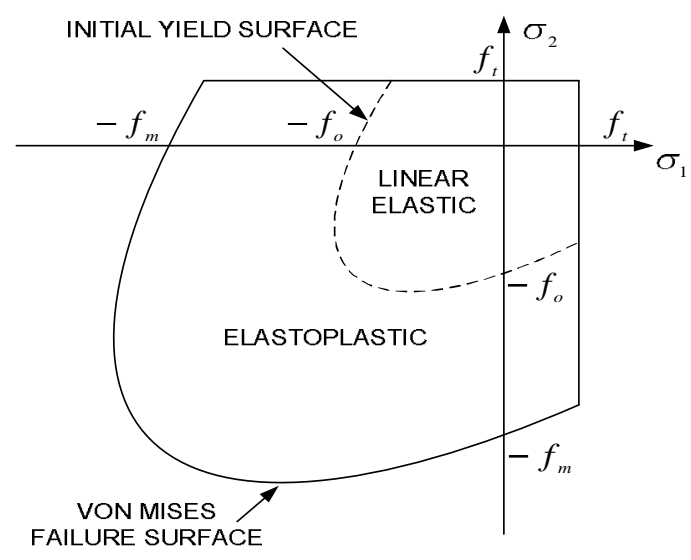

Fig.(3) Yield and failure surface

\subsection{Mortar joints}

Interface element with six node as shown in Fig.4 permit discontinuities in the displacement field and their behavior is described in terms of a relation between the traction, and relative displacement, $\Delta u$, across the interface.

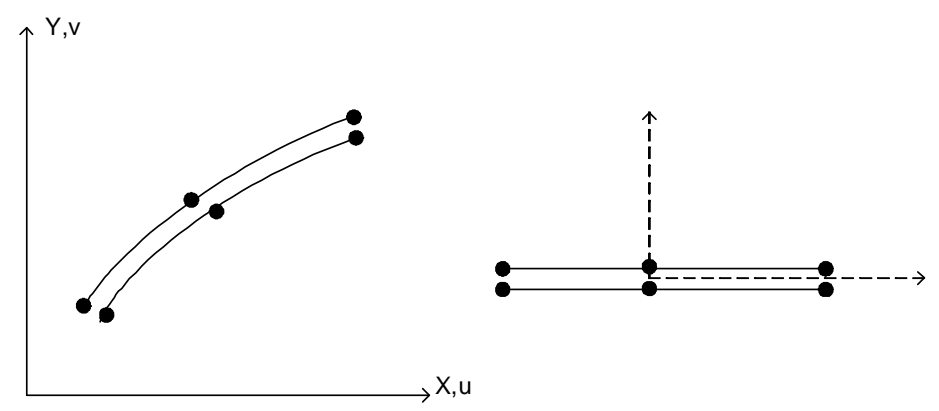

Fig.( 4) Interface element

The linear elastic relation between these generalized stress and strains can be written in the standard form as:

$\sigma=D^{e} \varepsilon$

Where $\sigma=\{\sigma, \tau\}^{T}, D^{e}=\operatorname{dig}\left\{K_{n}, K_{s}\right\}$ and $\varepsilon=\left\{\Delta u_{n}, \Delta u_{s}\right\}^{T}$, with $\mathrm{n}$ and s denote the normal and shear components, respectively. The elastic stiffness matrix $D^{e}$ can be obtained from the properties of the two masonry components (unit and mortar) and the mortar thickness of the joint .Due to the zero thickness inherent to the interface element formulation, the size of the unit has to be expanded by the mortar thickness, $h_{m}$, in both direction (vertical and horizontal) as shown in Fig. 5. Due to relative dimensions of mortar and unit, it is assumed that the elastic properties of the unit remain unchanged. 


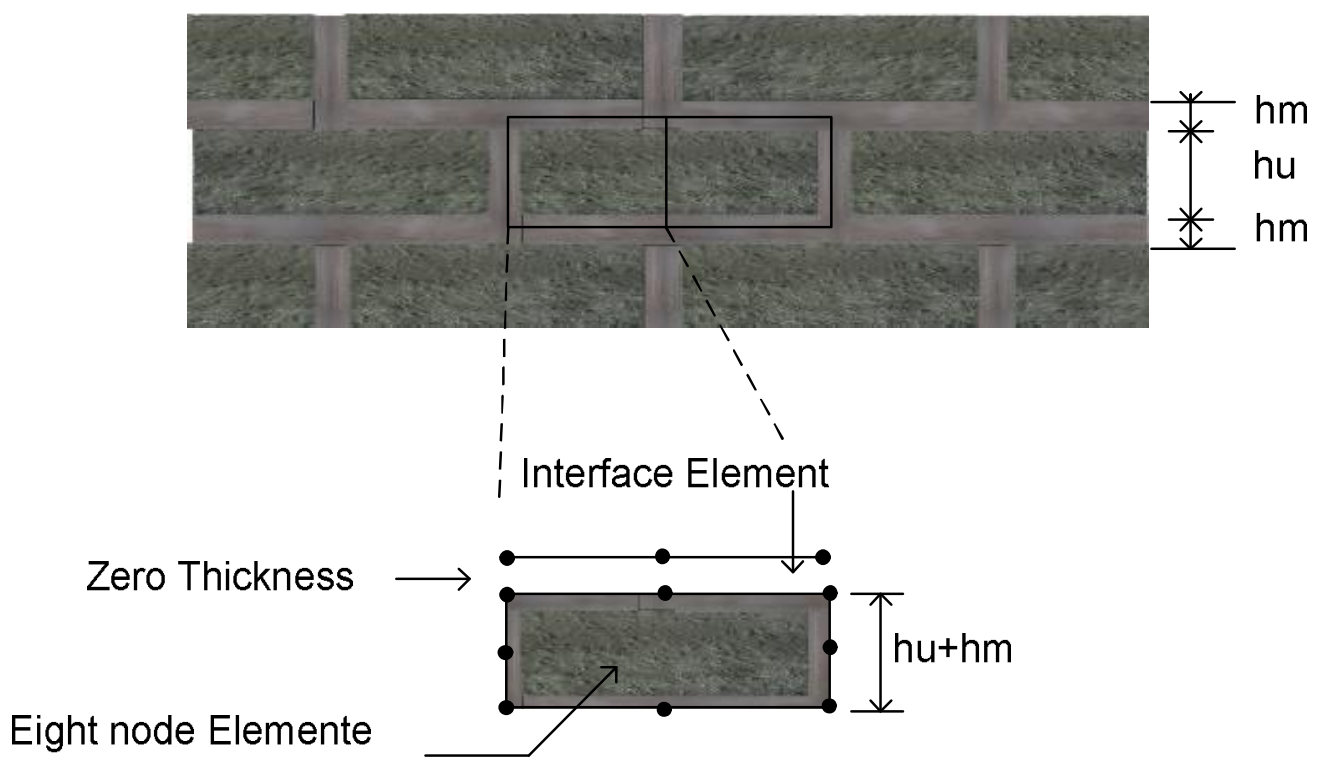

Fig.(5) Suggested modeling strategy. Units $(u)$, which are expanded in both directions by the mortar thickness, are modeled with continuum elements. Mortar joints $(m)$ and potential cracks in the units are modeled with zero-thickness interface elements.

The normal and shear stiffness required to define the material property matrix of the element, can be represented by the following expressions [7].

$$
K_{n}=\frac{E_{u} \cdot E_{m}}{h_{m}\left(E_{u}-E_{m}\right)} \quad, \quad K_{s}=\frac{G_{u} \cdot G_{m}}{h_{m}\left(G_{u}-G_{m}\right)}
$$

Where $E_{u}$ and $E_{m}$ are the young's modules, $G_{u}$ and $G_{m}$ are the shear moduli, respectively , for unit and mortar and $h_{m}$ is the actual thickness of the joint.

The stiffness values obtained from formula do not correspond to a penalty approach, which means that overlap of neighboring units subjected to compression will become visible. This feature is, however, intrinsic to the interface elements formulation and is independent of the values of normal stiffness, even if it is clear that the amount of penetration will be higher with decreasing interface stiffness. The interface model includes a compressive cap where the complete inelastic behavior of masonry in compression is lumped. This is a phenomenological representation of masonry crushing because the failure process in compression is, in reality, explained by the microstructure of units and mortar and the interaction between them. For dry joint of masonry wall, when the mortar not used between units, the stiffness must be represented by the following expressions.

$$
K_{n}, \text { jo int }=\frac{1}{h\left[\frac{1}{E_{\text {wall }}}-\frac{1}{E_{\text {brick }}}\right]} \quad, \quad K_{s}, \text { jo int }=\frac{K_{n}, \text { jo int }}{2(1+v)}
$$

Where $\mathrm{h}$ is the height of the block, $E_{\text {wall }}$ is the young's modulus of the wall and $E_{\text {brick }}$ is the young's modulus of the brick and $v$ is the Poisson's ratio.

The elastic domain is bounded by a composite yield surface that includes tension, shear and compression failure see Fig.6. This model was developed by Lourenco [ 7 ]. This model has been developed within the flow theory of plasticity. The composite yield surface is defined by three yield functions, where softening behavior has been included for all modes(tension, shear and compression modes). 


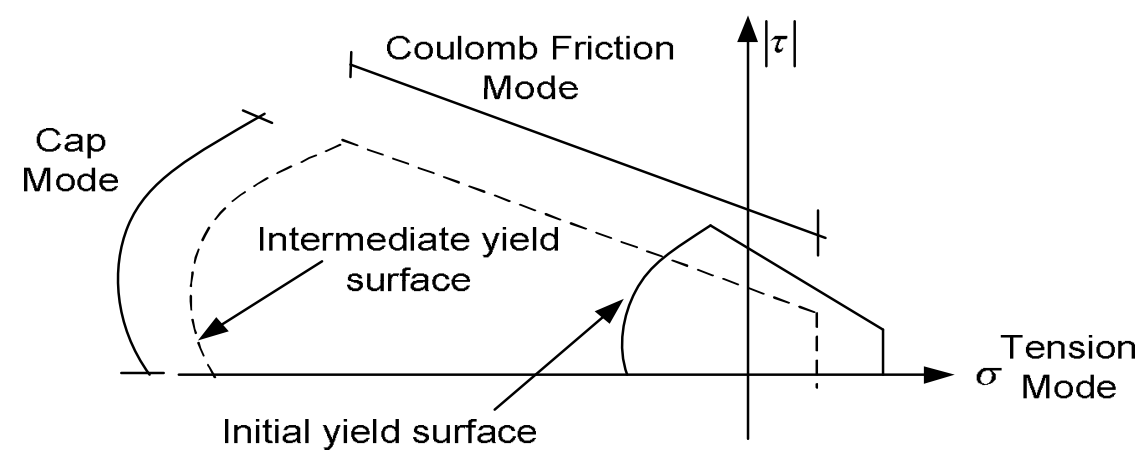

Fig.(6) Adopted model for interfaces. an “interface cap model”. [8]

The stress rate vector can be expressed as:

$\sigma=D^{e} \varepsilon^{e}=D^{e}\left(\varepsilon-\varepsilon^{p}\right)$

(5)

And the following yield functions have been adopted:

Tension criterion: $f_{t}\left(\sigma, K_{t}\right)=\sigma-\bar{\sigma}_{t}\left(K_{t}\right)$

(6)

Coulomb friction criterion: $f_{s}\left(\sigma, K_{s}\right)=|\tau|+\sigma \tan \phi-\bar{\sigma}_{s}\left(K_{s}\right)$

Compression cap criterion: $f_{c}\left(\sigma, K_{c}\right)=\left(\sigma^{T} P \sigma\right)^{1 / 2}-\bar{\sigma}_{c}\left(K_{c}\right)$

(8)

Where $\phi$ represents the friction angle and $P$ is the projection diagonal matrix

$\operatorname{diag}\left\{2 C_{n n}, 2 C_{s s}\right\}$ with $C_{s s}$ and $C_{n n}$ a set of material parameters. $\bar{\sigma}_{t}, \bar{\sigma}_{s}$ and $\bar{\sigma}_{c}$ are the isotropic effective stress of each of the adopted yield functions, ruled by scalar internal variables $K_{t}, K_{s}$ and $K_{C}$. The evaluation lows of these internal variables are giving by:

$$
K_{t}=\left|\Delta u_{n}\right|=\lambda_{t}, K_{s}=\left|\Delta u_{t}\right|=\lambda_{s}, \quad K_{c}=\frac{\sigma^{T} \varepsilon^{P}}{\bar{\sigma}_{c}}=\lambda_{c}
$$

(9)

And the plastic strain rate vector reads:

$\varepsilon^{P}=\lambda \frac{\partial g}{\partial \sigma}$

(10)

Where $\lambda$ is the plastic multiplier rate, $g$ is the plastic potential function. Associated flow rule is assumed for tensile and cap modes and anon-associated plastic potential $g_{s}$ is adopted for the shear mode with a dilatancy angle $\psi$ and cohesion $C$, given by

$g_{t}=f_{t}, g_{s}=|\tau|+\sigma \tan \psi-C, g_{c}=f_{c}$

(11)

In the particular case of dry masonry joints, the tensile strength and cohesion of the joints are assumed to be equal to zero 


\subsubsection{Integration of the elasto plastic equation:}

The return mapping algorithm [9] in strain is driven and basically consists of two steps, first the calculation of the elastic trial stress, also called the elastic predictor, and scond the return mapping to the yield surface, the plastic corrector.

The stress update for each individual yield surface is obtained as [10]:

$$
\sigma_{n+1}=\sigma_{n}+\Delta \sigma_{n+1}=\sigma_{n}+D \Delta \varepsilon_{n+1}^{e}=\sigma_{n}+D\left(\Delta \varepsilon_{n+1}-\Delta \varepsilon_{n+1}^{P}\right.
$$

This equation can be recast as:

$$
\sigma_{n+1}=\sigma_{n+1}^{\text {Trial }}-\left.\Delta \lambda_{n+1} D \frac{\partial g}{\partial \sigma}\right|_{n+1}
$$

Further more, since $\sigma_{n+1}$ and $K_{n+1}$ can be expressed as function of $\Delta \lambda_{n+1}$, the yield function is transformed into nonlinear equation of one variable $f\left(\Delta \lambda_{n+1}\right)=0$, which is solved locally using the Newton-Raphson method. Considering that only one surface is active.

The consistent tangent stiffness matrix for each individual surface is obtained according to:

$$
D^{e p}=\frac{d \sigma}{d \varepsilon}=H-\frac{H \cdot \frac{\partial g}{\partial \sigma} \cdot \gamma^{T} \cdot H}{h+\gamma^{T} \cdot H \cdot \frac{\partial g}{\partial \sigma}}
$$

Where

$$
H=\left[D^{-1}-\Delta \lambda_{n+1} \frac{\partial^{2} g}{\partial \sigma^{2}}\right] \quad, \gamma=\frac{\partial f}{\partial \sigma}+\left.\frac{\partial f}{\partial K} \cdot \frac{\partial K}{\partial \sigma}\right|_{n+1} \quad h=-\left.\frac{\partial f}{\partial K} \frac{\partial K}{\partial \Delta \lambda}\right|_{n+1}
$$

In the described composite yield criterion, the intersection of the different yield surfaces defines two possible corners, see Fig. 7, composed by the tensile and shear modes or by the shear and cap modes, due to the intersection between cap and tensile modes is numerically prevented from occurring.

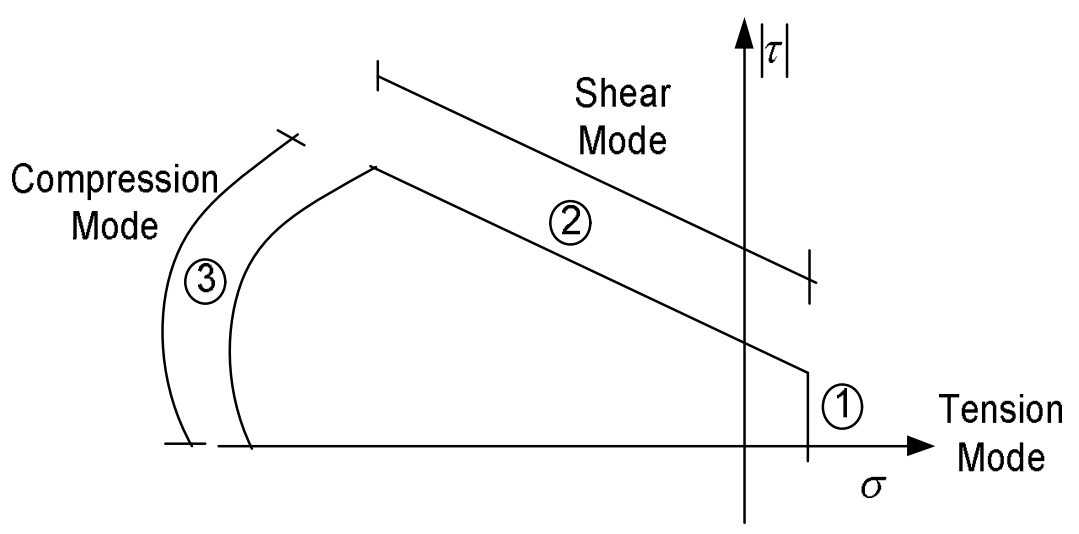

Fig.(7) Composite yield surface [7]

In this model, tensile and shear softening are coupled because, physically, both phenomena are related with the degradation of bond between the unit and the mortar and due to physical reasoning, shear and cap modes are assumed to be uncoupled, since phenomena that rule the 
hardening/softening of each mode seem to be only lightly related. Thus equations (9) 2,3 remain unchanged.

The plastic strain rate in the corner is given by a linear combination of plastic strain rates of yield surfaces $\mathbf{1}$ and $\mathbf{2}$

$\varepsilon_{p}=\varepsilon_{1}^{p}+\varepsilon_{2}^{p}=\lambda_{1} \frac{\partial g 1}{\partial \sigma}+\lambda_{2} \frac{\partial g 2}{\partial \sigma}$

At this corner, quadratic combination for the hardening parameters rate

is adopted, which read,

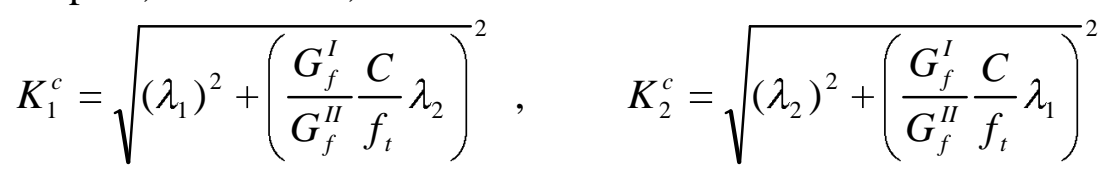

Where $G_{f}^{I}$ is fracture energy (from tension test) for mode I and $G_{f}^{I I}$ is fracture energy (from shear test) for mode II.

The stress update is then given by

$$
\sigma_{n+1}=\sigma_{n+1}\left(\Delta \lambda_{1, n+1}, \Delta \lambda_{2, n+1}\right)=\sigma_{n+1}^{\text {Trial }}-\left.\Delta \lambda_{1, n+1} D \frac{\partial g 1}{\partial \sigma}\right|_{n+1}-\left.\Delta \lambda_{2, n+1} D \frac{\partial g 2}{\partial \sigma}\right|_{n+1}
$$

For the corner regime, the Euler backward algorithm [10] can be simply expressed in a system of two nonlinear equations on the variables $\Delta \lambda_{1, n+1}$ and $\Delta \lambda_{2, n+1}$

$$
\begin{aligned}
& f_{1, n+1}\left(\Delta \lambda_{1, n+1}, \Delta \lambda_{2, n+1}\right)=0.0 \\
& f_{2, n+1}\left(\Delta \lambda_{1, n+1}, \Delta \lambda_{2, n+1}\right)=0.0
\end{aligned}
$$

These equation are Solved by a Newton-raphason procedure. The Jacobian matrix is given in Lourenco [8].For multi-surface plasticity an expression equivalent to Equation (14) can also be obtained. The reader is referred to Lourenco [8], where such expression can be found.

\subsubsection{A nonlinear Solution Technique}

The global nonlinear equations of equilibrium are solved using an incrementaliterative technique performed under displacement control by using arc-length method. iterative techniques use the standard and modified Newton-Raphson method. An automatic load incrimination scheme is included. As shown in the previous section the theory of multi surface plasticity is used to define the material behavior of interface element. Unconditionally Elure backward algorithms are derived for all models of the cap model. The Eluer backward return mapping is solved using a local Newton-Raphson method for nonlinear equations of interface element only. A rail and error procedure to solve the return mapping is used. For each step, the following algorithm is performed [11]:

1- Compute elastic trail stresses $\left(\sigma^{o}\right)$. Check for plastic behavior;

If $f\left(\sigma_{n+1}, K_{n+1}\right) \leq 0$, the integration point is elastic, update stresses and strain, Exit;

If $f\left(\sigma_{n+1}, K_{n+1}\right)>0$, the integration point is plastic see Fig.8;

2- If the integration point is plastic;

Iterations $\mathrm{J}=0 \ldots \mathrm{n}$

$$
\begin{aligned}
& \Delta \lambda=\frac{f\left(\sigma^{j}\right)}{\left((\partial f / \partial \sigma)^{j}-D(\partial g / \partial \sigma)^{j}\right.} \\
& \Delta \sigma^{p}=\Delta \lambda D(\partial g / \partial \sigma)^{j}
\end{aligned}
$$




$$
\begin{aligned}
& \sigma^{j+1}=\sigma^{j}-\Delta \sigma^{p} \\
& \text { Until } f\left(\sigma_{n+1}, K_{n+1}\right)<\text { Tolerance }
\end{aligned}
$$

if a converged state is found compute consistent tangent operator.

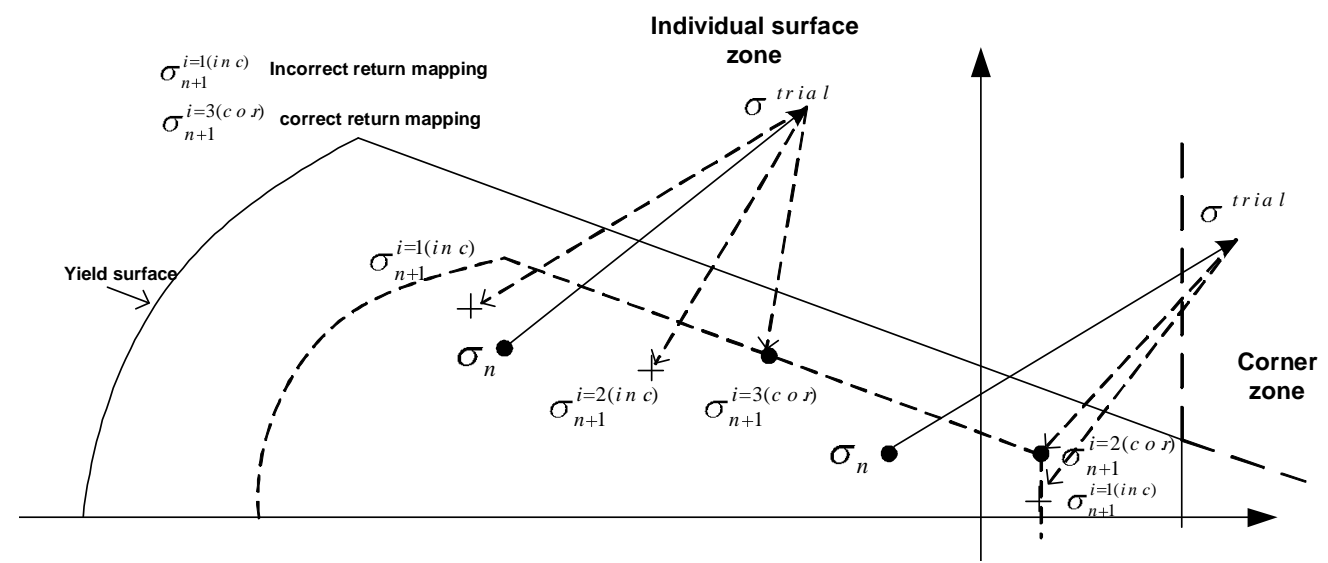

Fig.(8) Return mapping algorithm (different case).

\section{Numerical Examples}

\section{Confined masonry wall}

A two masonry shear walls with same property and dimension (J4D, J5D) was carried out by Raijmakers and Vermeltfoort [8]. The width /height ratio (L/H) of shear walls is $990 / 1000(\mathrm{~mm} / \mathrm{mm})$; the walls were built up with 18 courses of bricks, from which 16 courses were active and 2 were clamped a stiff steel beam, Fig.9. The brick dimensions are $210 * 52 * 100 \mathrm{~mm}^{3}$ and the mortar joints are $10 \mathrm{~mm}$ thick. The vertical load $\left(P=0.3 \mathrm{~N} / \mathrm{mm}^{2}\right)$ was applied on the top and their resultant was kept constant during the complete horizontal loading procedure. The stiff steel beam did not allow rotations of the top and was subsequently pushed within increasing horizontal force. The micro-properties for the different materials according to Lourenco [8] are given in table.1 and table.2.

\begin{tabular}{|c|c|c|c|}
\hline \multicolumn{2}{|c|}{ Brick } & \multicolumn{2}{|c|}{ Joint } \\
\hline$E$ & $v$ & $K_{n}$ & $K_{s}$ \\
\hline 16700 & & 82 & 36 \\
\hline$\left[\mathrm{N} / \mathrm{mm}^{2}\right]$ & 0.15 & {$\left[\mathrm{~N} / \mathrm{mm}^{3}\right]$} & $\mathrm{N} / \mathrm{mm}^{3}$ \\
\hline
\end{tabular}

Table.1 Elastic properties for the bricks and joints.

Table .2 Inelastic properties for the joints.

\begin{tabular}{|c|c|c|c|c|c|c|c|}
\hline \multicolumn{2}{|c|}{ Tension } & \multicolumn{5}{c|}{ Shear } & \multicolumn{2}{c|}{ Cap } \\
\hline$f_{t}$ & $G_{f}^{I}$ & $C$ & $\tan \phi$ & $\tan \psi$ & $G_{f}^{I I}$ & $f_{m}$ & $C_{s s}$ \\
\hline $\begin{array}{c}0.25 \\
\mathrm{~N} / \mathrm{mm}^{2}\end{array}$ & 0.018 & $1.4 f_{t}$ & 0.75 & 0.0 & $\left.\begin{array}{c}0.125 \\
{\left[\mathrm{Nmm} / \mathrm{mm}^{2}\right.}\end{array}\right]$ & $\left.\begin{array}{c}10.5 \\
{\left[\mathrm{~N} / \mathrm{mm}^{2}\right.}\end{array}\right]$ & 9.0 \\
{$\left[\begin{array}{c}\mathrm{N} / \mathrm{mm}^{2}\end{array}\right]$} & & & \\
\hline
\end{tabular}




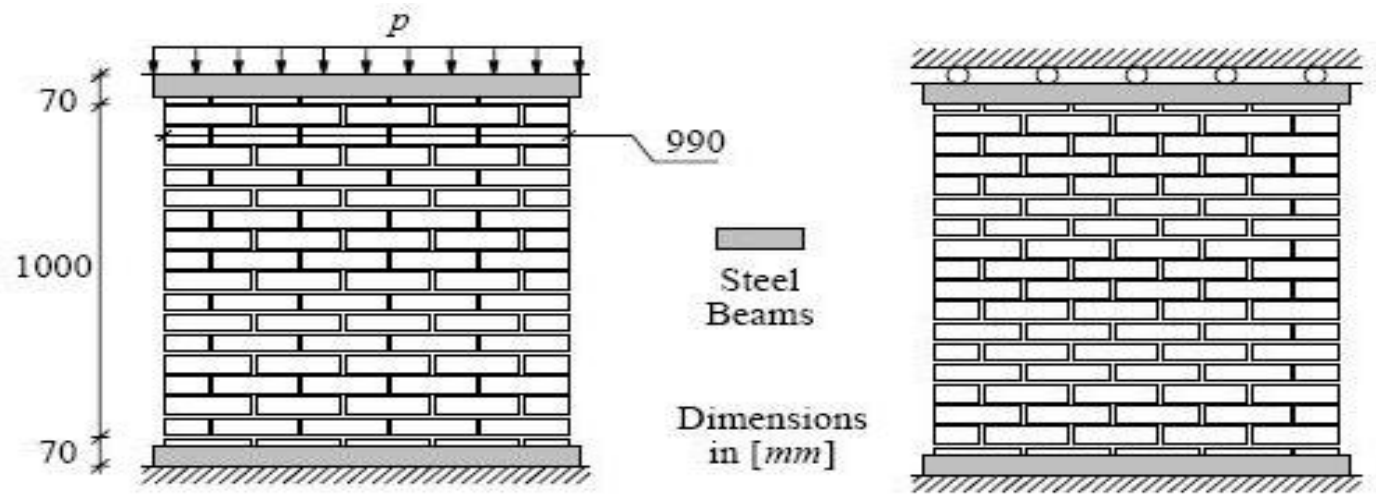

Fig. (9) Loads Walls: (a) phase 1 - vertical loading;

(b) phase 2 - horizontal loading under displacement control[8].

The crack patterns for the walls tested are shown in Fig. 10 while the finite element mesh system is shown in Fig. 11.

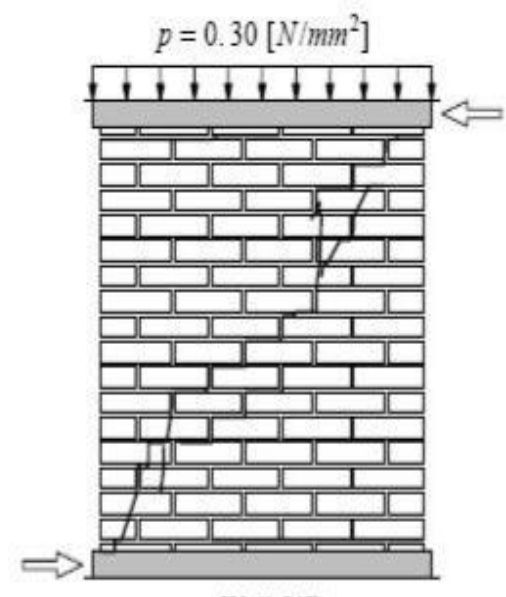

Wall J4D

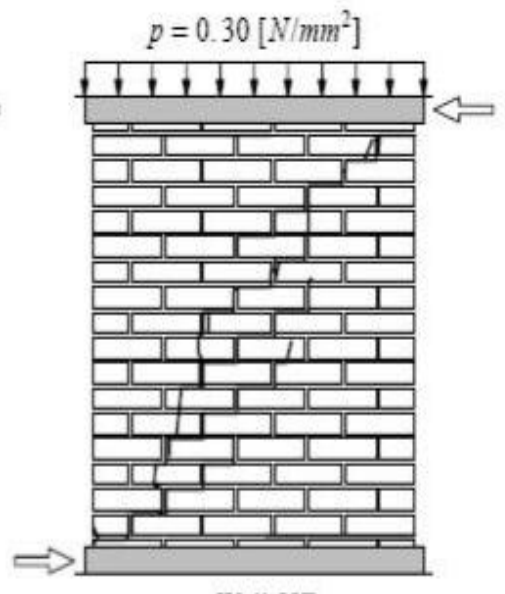

Wall J5D

Fig.(10) Walls Experimental crack Wall

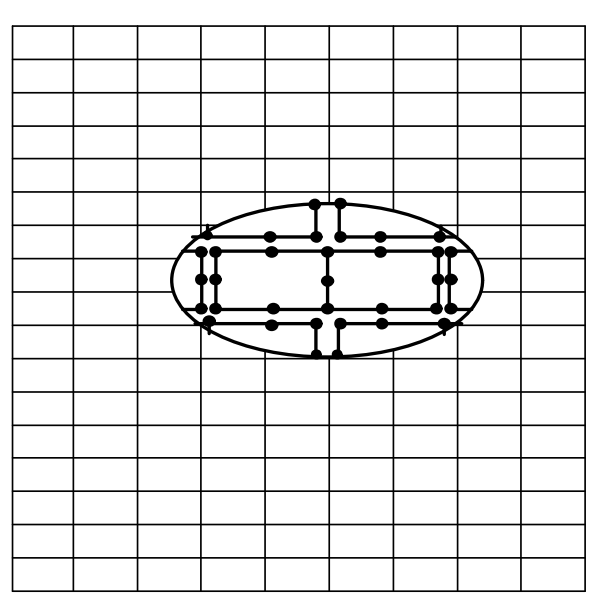

Fig.(11) Finite Element Meshes of -patterns for different tests[8].

Fig.12 present the horizontal load-displacement curves for the top steel beam for the wall studied. In this figure, the experimentally obtained results are compared with the numerical analysis. This gives a good impression about the numerical implementation because it is possible to trace the response of the structure through initial cracking, failure loads behavior. The comparison with the experimental failure loads is shown, good agreement is found since the difference between predicted and observed result is less than $3 \%$.

Fig.13 shows the deformed shapes of the finite element models at $0.75 \mathrm{~mm}$ and $3.0 \mathrm{~mm}$, respectively. This figure shows opening and slip along the mortar joints. the crack starts in the middle of the wall under increasing deformation, and progresses in the direction of the supports and ,finally a collapse mechanism is formed with crushing of the compressed toes and under the steel beam at the top. 


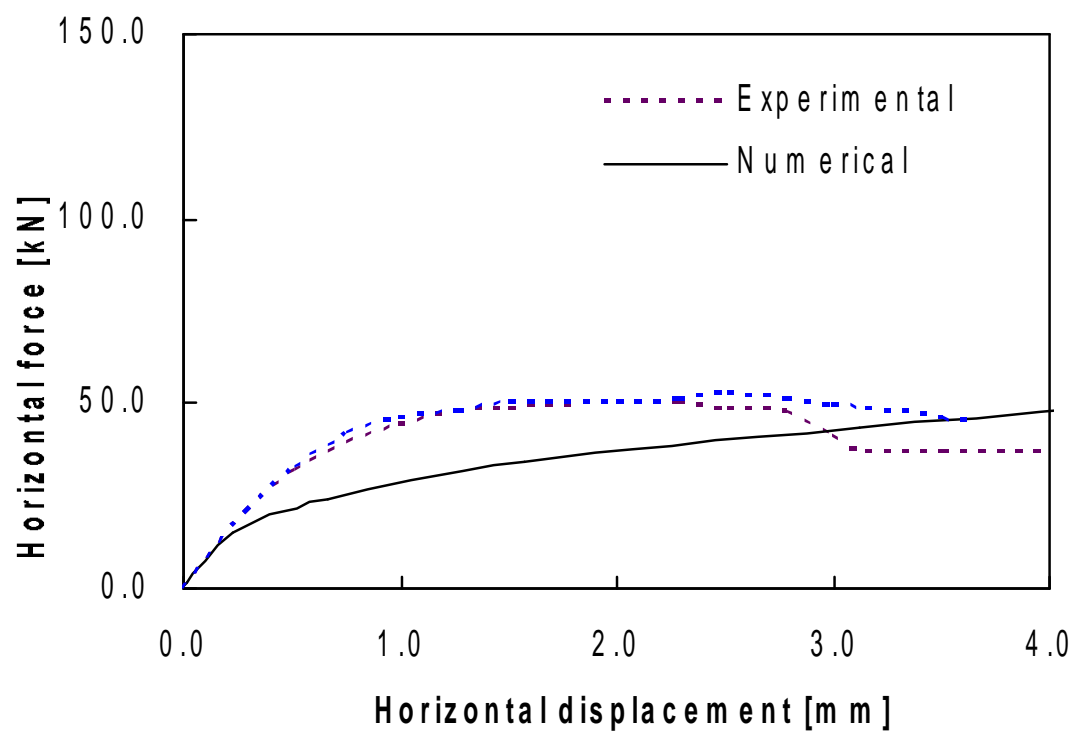

Fig.(12) Load-displacement diagram.

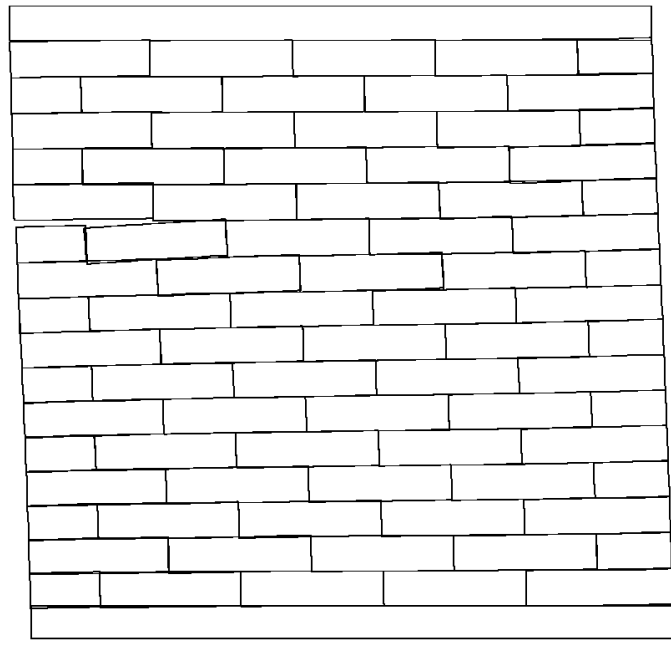

(a)

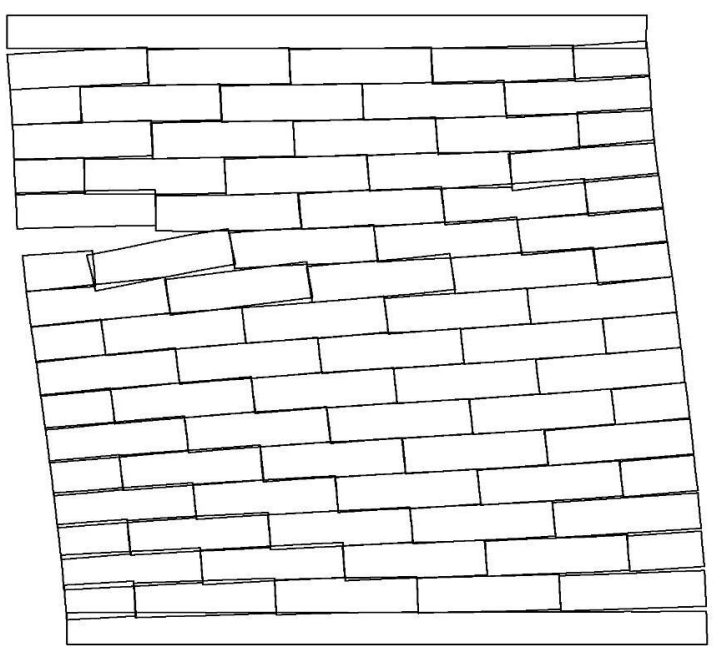

(b)

Fig.( 13) Deformed mesh for JD wall at horizontal displacement equal to: (a) 0.75 mm; (b) 3.0 mm.'

\section{Unconfined masonry wall}

The analyzed wall has a thickness of $200 \mathrm{~mm}$, with square panel $1000 * 1000 \mathrm{~mm}^{2}$ and made of stone blocks laid without mortar between them for two masonry wall with same property and dimension tested by Oliveira [12] as shown in Fig.14.in addition to the dead weight, the walls were first loaded by a vertical load of $30 \mathrm{kN}$ applied at the top, after which a horizontal load was progressively applied at the top beam. The experimental crack patterns for the tested walls are shown in Fig.15. In the particular case of dry stone masonry joints, the tensile strength and cohesion are assumed to be equal to zero. The material property are given in table. 3 and table.4. 
Table.3 Elastic properties for the bricks and joints.[12]

\begin{tabular}{|c|c|c|c|}
\hline \multicolumn{2}{|c|}{ Brick } & \multicolumn{2}{|c|}{ Joint } \\
\hline$E$ & $v$ & $K_{n}$ & $K_{s}$ \\
\hline 15500 & & 5.87 & 2.45 \\
\hline$\left[\mathrm{N} / \mathrm{mm}^{2}\right]$ & 0.15 & $\mathrm{~N} / \mathrm{mm}^{3}$ & $\mathrm{~N} / \mathrm{mm}^{3}$ \\
\hline
\end{tabular}

Table .4 Inelastic properties for the joints.

\begin{tabular}{|c|c|c|l|l|}
\hline \multicolumn{3}{|c|}{ Shear } & \multicolumn{2}{c|}{ Cap } \\
\hline $\tan \phi$ & $\tan \psi$ & $G_{f}^{I I}$ & $f_{m}$ & \multicolumn{1}{c|}{$C_{s s}$} \\
\hline 0.62 & 0.0 & $\left.\begin{array}{c}0.125 \\
{\left[\mathrm{Nmm} / \mathrm{mm}^{2}\right.}\end{array}\right]$ & 6.0 & 2.0 \\
& & $\left.\mid \mathrm{N} / \mathrm{mm}^{2}\right\rfloor$ & \\
\hline
\end{tabular}

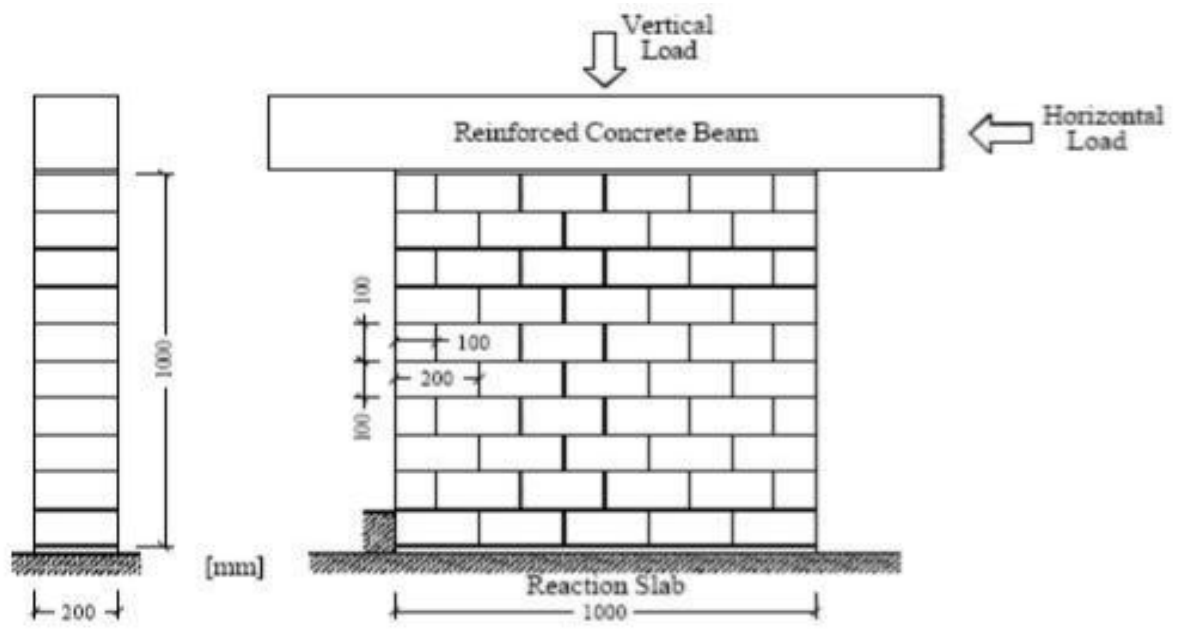

Fig.(14) Adopted geometry for the dry stone masonry walls and schematic loading arrangement[12].

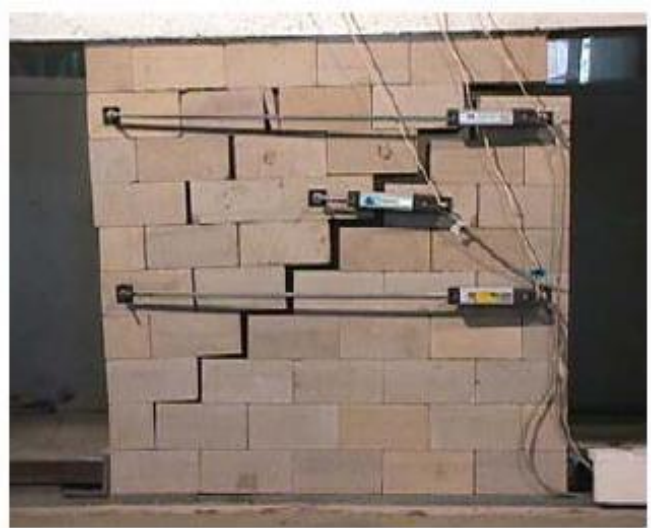

SW30.1

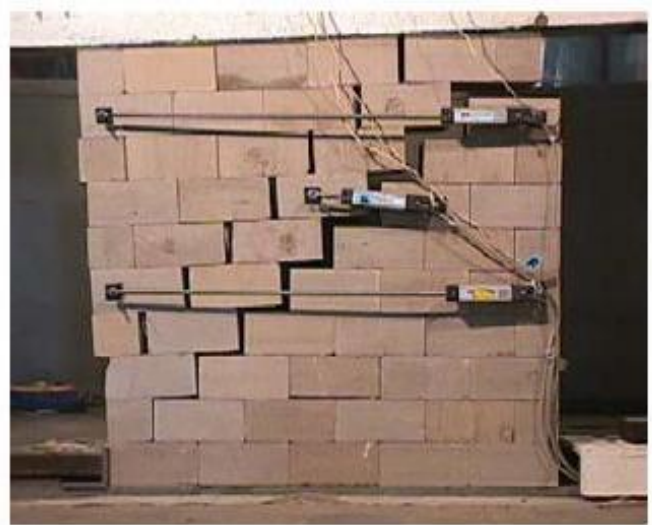

SW30.2

Fig.(15) Experimental crack patterns for different tests [12]. 


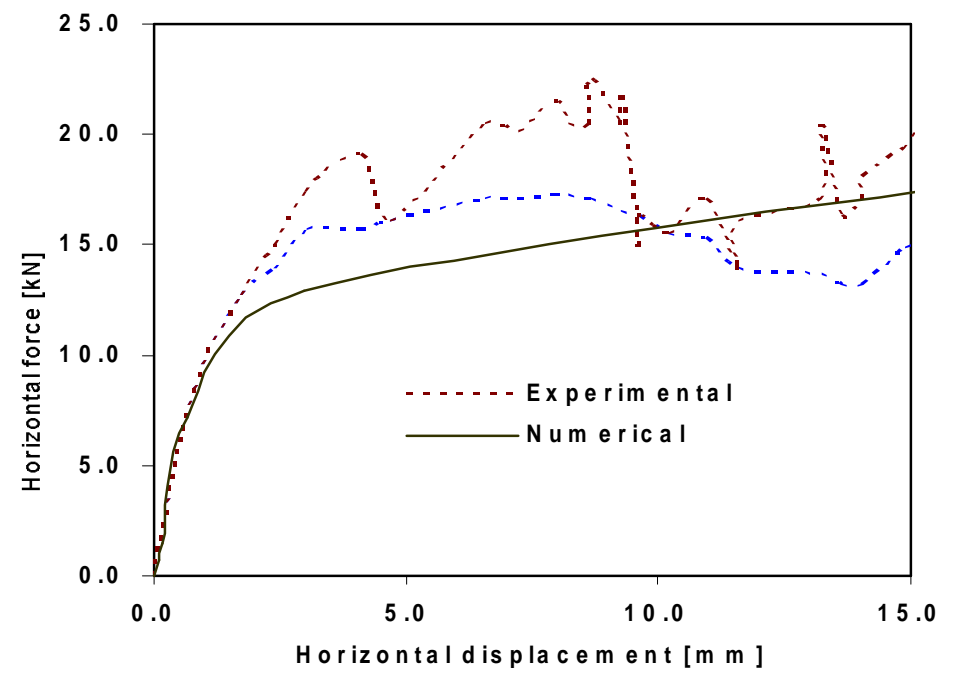

Fig.(16) Comparison of curves relating the horizontal force $(\mathrm{H})$ with the horizontal displacement for walls SW30.1 and SW30.2.

Fig. 16. Illustrates the load-displacement diagram from the tested wall and the numerical results, up to a displacement of $15 \mathrm{~mm}$. the agreement between experimental and numerical responses can be considered satisfactory.

Globally, the analysis captures well the experimental behavior of the walls, as illustrated in Fig. 17 together with the global load-displacement response, a comparison in terms of the deformed mesh and failure pattern is necessary to appraise the quality of the numerical analysis. At initial horizontal load, see Fig. 17 it is possible to observe that separation of the block through diagonal cracks gradually progresses from the bottom courses to the top, finally overturning failure mechanism is found with a complete diagonal crack through head and bed joints

(a)

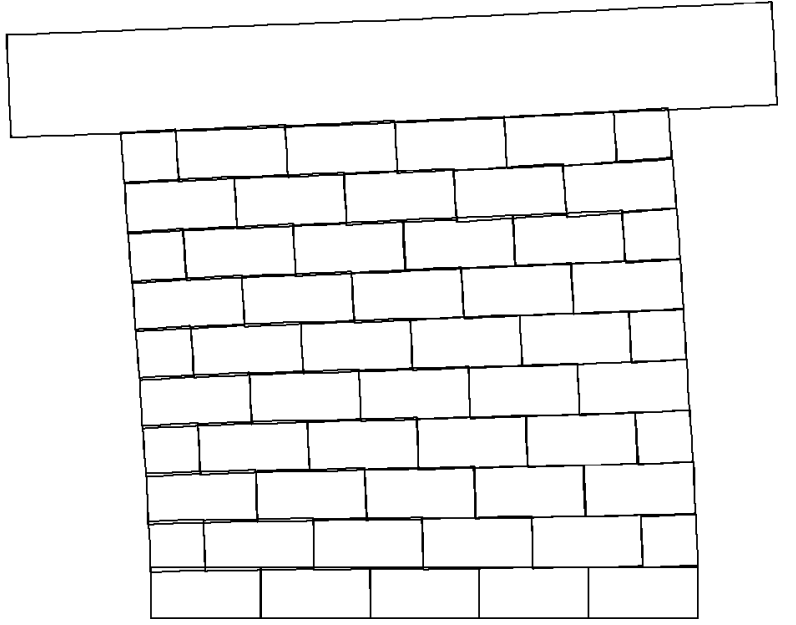

(b)

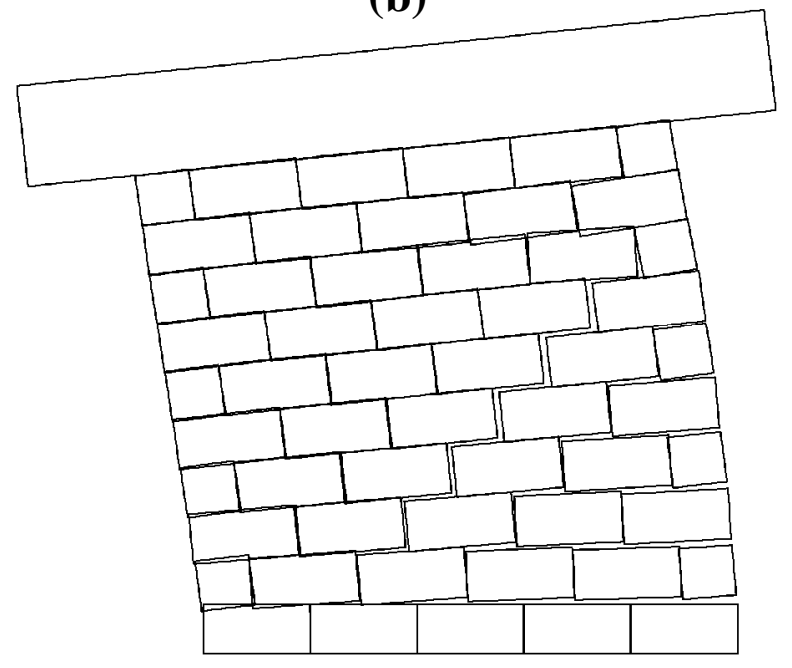

Fig.(17) Deformed mesh for SW wall at horizontal displacement equal to : (a) $0.75 \mathrm{~mm}$ ; (b) $3.0 \mathrm{~mm}$. 


\section{Conclusions:}

This study presents an efficient finite element analysis technique which shows a great versatility in analysis complex discontinuities in the analysis of masonry walls structures by use of interface elements with a constitutive model entirely established on the basis of the incremental theory of plasticity to simulate the actual behavior at the interface between contacting materials.

A comparison between numerical and experimental result was also given. It was shown that the finite element method model was able to predict effectively the behavior of masonry structures, with both confined and unconfined masonry wall, as well as sufficiently accurate collapse load values.

\section{Reference}

1-Milani, G., Lourenço, P.B., Tralli, A., " Homogenised Limit Analysis of Masonry Wall, Part I: failure Surface" ,Computers \& Structures, 84(3-4),2006, pp. 166-180.

2-Asteris, P.G., Syrmakezis, C.A. "'Strength of Unreinforced Masonry Walls Under Concentrated Compression Loads" , Practice Periodical on Structural Design and Construction, ASCE, Vol. 10, No. 2, 2005, pp. 133-140.

3-Tzamtzis, A.D, Asteris P.G., "Finite Element Analysis of Masonry Structures: Part I-

Review of Previous Work", Proceedings, Ninth North American Masonry Conference, South Carolina ,June 2003.

4-Page, A.W., "Finite Element Model For Masonry Structure", J. Struct. Division ASCE, Vol.104, No.8, 1978, pp.1267-1285.

5-Ali, S. and Page, A., W.," Finite Element Model for Masonry Subjected to Concentrated Loads", J., Struct. Division ASCE, Vol.114, No.8, 1988, pp.1761-1784.

6-Al-Chaar,G.K and Mehrabi , A.B., "Constitutive Models for Nonlinear Finite Element Analysis of Masonry Prisms and Infill Walls",ERDC/CERL TR-0819.Champaign,IL:Engineer Research and Development Center-Construction Engineering Research Laboratory,2008.

7-Lourenco, P.B., "Analysis of Masonry Structures with Interface Elements Theory and Application”. Report N ${ }^{\circ}$ 03.21.22.0.01, Delft University of Technology, Delft, The Netherlands, 1994.

8-Lourenco, P.B., Rots, J.G., “A Multisurface Interface Model for Analysis of Masonry Structures" J. Eng. Mech., ASCE ,Vol. 123,No.7, 1997, pp. 660-668.

9-Chen, W. F., Lan , Y. M. and Sotelino, E. D. ,"The Strain-Space Consistent Tangent Operator and Return Mapping Algorithm for Constitutive Modeling of Confined Concrete" International Journal of Applied Science and Engineering, Vol.1, No.1, 2003, pp.17-29.

10-Zienkiewicz,O.C. and Taylor ,R.L.,"The Finite Element Method for Solid and Structural Mechanics", Sixth edition,2005.

11-Alfaiate.J. V., de Almeida, J. R. and Gago, A. S., "On the Numerical Analysis of Localized Damage in Masonry Structures" In 2nd International Conference on Structural Engineering and Construction (ISEC-02), Franco Bomtempi (Ed.), 769-774., Roma, 2003.

12-Oliveira, D.V., "Mechanical Characterization of Stone and Brick Masonry", Report 00-DEC/E-4, Universidade do Minho.Gumaraes,Portugal, .2000. 